Journal of Animal and Veterinary Advances 11 (14): 2384-2391, 2012

ISSN: $1680-5593$

(C) Medwell Journals, 2012

\title{
Isolation and Identification of Haemophilus parasuis and Establishment of its Detection Method of Indirect ELISA
}

\author{
${ }^{1}$ Zhong Fei, ${ }^{1,2}$ Wang Yin, ${ }^{1} \mathrm{Li}$ Li-Rui, ${ }^{1}$ Huang Hai-Yan, ${ }^{1}$ Song Yong, \\ ${ }^{1}$ Yang Ze-Xiao and ${ }^{1}$ Yao Xue-Ping \\ ${ }^{1}$ School of Animal Medicine, Schuan Agricultural University, \\ 625014 Sichuan Ya'an, P.R. China \\ ${ }^{2}$ Sichuan Province Important Laboratory on Epidemic Animal Diseases and Human Health, \\ 625014 Sichuan Ya'an, P.R. China
}

\begin{abstract}
To provide the evidence for detection and epidemical investigation of Haemophilus parasuis by means of isolation and identification of Haemophilus parasuis and study on its detection method of ELISA. From the pathological specimens collected from several scaled-up pig farms, the strain of Haemophilus parasuis was isolated identified by means of observation of cultural characteristics and morphology and structure, Biochemical tests, Antibiotic Susceptibility tests, PCR identification and serovar identification. Subsequently, indirect ELISA Method of Haemophilus parasuis antibody for detection was studied by utilizing the isolated strain bacteria of treated with ultrasonication as the antigen with preparation of positive serum, optimization of concentration of the coating antigen, concentration of the secondary antibody and reaction time and Susceptibility test, Specificity test and Repeatability test. A strain of Haemophilus parasuis serovar 5, named as SCHPS5 which is sensitive to cephalosporin IV, cefotaxime, sulbactam, furaxone, chloromycetin. The detection sensitivity of the target antibody in indirect ELISA Method based on this isolate can reach over 1:10000 and this detection method has high specificity and high repeatability. This study has provided scientific evidence and a reliable antibody detection method for prevention and treatment of the disease resulting from Haemophilus parasuis.
\end{abstract}

Key words: Haemophilus parasuis, isolation and identification, indirect ELISA, serum, bacteria

\section{INTRODUCTION}

Haemophilus parasuis disease is multiple pig serositis and arthritis caused by Haemophilus parasuis whose main symptoms are fever, cough, respiratory distress, maransis, claudication, ataxia and coarse and disorderly hair. Pathological changes in anatomic examination exhibit as pleuritis, pneumonia, pericarditis, peritonitis, arthritis and meningitis (Straw et al., 1998). In addition, Haemophilus parasuis may cause hematosepsis and probably lead to sequela, i.e., abortion in female pigs and chronic claudication in male pigs.

This disease was reported by Glasser for the first time in 1910 and so was also called Glasser's disease which exhibits global transmission and has become one of bacterial diseases which influence on the global pigfeeding industry (Oliveira et al., 2001; Oliveria and Pijioan, 2004). In China the pathogen was isolated from some scaled-up pig farms. Haemophilus parasuis only infects pigs, those at the age of 2 weeks to 4 months are susceptible and usually those at the age of 5-8 weeks after ablactation are ready to have this disease. The morbidity is generally $10-15 \%$ and if more seriously the mortality can reach 50\% (Oliveira, 2003). Invasion of Haemophilus parasuis may result in general diseases with high morbidity and mortality. In combined feeding of different droves or introduction of boars, presence of is a thorny problem (Zhou et al., 2009). In 2011 infection of Haemophilus parasuis broke out in several scaled-up pig farms in Sichuan and pig death occurred. In this study, routine isolation and identification of the pathological specimens submitted to examine was carried out and the method of indirect ELISA for detection of Haemophilus parasuis was established preliminarily by utilizing the isolated strain of as the antigen, by means of optimization of reaction conditions, Susceptibility test, Specificity test and Repeatability test.

\section{MATERIALS AND METHODS}

Pathological specimens: The lung, joint fluid, brain tissue and pericardial effusion and serum from pigs with this disease delivered for examination by several pig farm in Sichuan.

Corresponding Author: Wang Yin, School of Animal Medicine, Schuan Agricultural University, 625014 Sichuan Ya'an, P.R. China 
Micro-biochemical test tubes and paper discs for Antibiotic Susceptibility test, bought from Hangzhou Microbiology Reagent Corp., Ltd. newborn cattle serum, Nicotinamide Adenine Dinucleotide (NAD), secondary enzyme-labeled rabbit anti-pig IgG-HRP, bought from Chengdu Kebite Biotech Corp., Ltd. and 96-well ELISA plate, BSA, filtering units, bought from Ya' an Rui-Jin-Te Corporation.

Preparation of media: Chocolate-agar medium, freshblood-agar medium, Maconkey medium, basic agar medium, trypsin and soybean agar, trypsin and soybean broth and so on were prepared in accordance with the related standards.

Design of primers: The PCR primers for identification of Haemophilus parasuis described by Li et al. (2011) were adopted to send to Sangon Biotech (Shanghai) Co., Ltd. for synthesis. The obtained primers were diluted according to the directions and stored for use at $-20^{\circ} \mathrm{C}$.

Isolation culture of bacteria: In accordance with the methods described by Li et al. (2011), the collected pathological specimens were treated; basic agar medium, chocolate agar medium and fresh blood agar medium were prepared and the strain of Haemophilus parasuis was isolated. Those clones suspected to be Hps ones were inoculated on the TSA medium to perform purification culture and staining and microscopic examination until all the clones and bacterial morphology were consistent.

Biochemical test: The single clone was inoculated in the Micro-biochemical test tubes containing sucrose, phenylalanine, maltose, sorbol, mannitol, urase, citrate, lysine, ornithine, glucose, gluconic acid, respectively. To each biochemical test tube $1 \mu \mathrm{L}$ cattle serum and $1 \mu \mathrm{L}$ $\mathrm{NAD}$ (factor $\mathrm{V}$ ) were added to culture for $24-48 \mathrm{~h}$ at $37^{\circ} \mathrm{C}$. The results of biochemical reactions were observed and according to the results the suspected clones were taken out to carry out satellite phenomenon visualization.

PCR detection: PCR was undertaken by utilizing the designed primers. The PCR reaction system $(50 \mu \mathrm{L})$ contained: $2 \times$ PreMIX, $25 \mu \mathrm{L}$; upstream and downstream primers, $1.5 \mu \mathrm{L}$ each; pure liquid culture template, $1 \mu \mathrm{L}$; sterilized double distilled water, complemented up to $50 \mu \mathrm{L}$. Reaction conditions: pre-denaturing at $94^{\circ} \mathrm{C}$ for $4 \mathrm{~min}$; denaturing at $94^{\circ} \mathrm{C}$ for $30 \mathrm{sec}$, annealing at $58^{\circ} \mathrm{C}$ for $30 \mathrm{sec}$, extending at $72^{\circ} \mathrm{C}$ for $45 \mathrm{sec}, 30$ cycles in total; finally extending at $72^{\circ} \mathrm{C}$ for $10 \mathrm{~min}$. Electrophoresis of the PCR product with $1 \%$ agarose was performed to observe, the remaining product was stored at $4^{\circ} \mathrm{C}$.
Antibiotic Susceptibility test: At first, $400 \mu \mathrm{L}$ pure culture in the TSM culturing liquor was pipetted to spread on the TSA plate containing NAD and serum. Then, paper discs for Susceptibility test of 30 common antibiotics including penicillin, streptomycin and so on were stuck horizontally to the TSA plate to culture at $37^{\circ} \mathrm{C}$ for $24 \mathrm{~h}$ and finally the result was observed.

Animal test: Randomly 10 mice were divided into two groups, 5 mice for each and the first group was test group and the second group was control group of normal saline. With sterilized PBS buffer the pure cultured bacteria were washed off from the TSA plate and the obtained culture was diluted to the bacteria concentration of $1.0 \times 10^{9} \mathrm{cfu} \mathrm{mL} \mathrm{m}^{-1}$. The bacteria solution of $0.3 \mathrm{~mL}$ was injected intraperitoneally into each mouse and in the control group the same amount of normal saline was injected intraperitoneally. The mice were segregated and fed to observe death phenomenon. Died mice were dissected and tissue bacteria smears were made to conduct Gram staining for microscopic examination. The cardiac blood was collected from died mice to isolate and culture the target bacterium.

Serovar identification: The isolated strain obtained through purification culture was washed off the TSA plate to prepare bacteria suspension in normal saline. Detection was carried out according to the method described in the directions of Standard Serum kit of Haemophilus parasuis.

\section{Preparation of serum}

Preparation of antigen (culture of the strain): The pure culture strain was picked up to streak on the TSA plate. After culture the single clone was picked up to inoculate in the liquid TSB medium and then culture on a shaker at $37^{\circ} \mathrm{C}$ for $16 \mathrm{~h}$. Suitable amount of the bacteria solution was taken to inoculate in the fresh TSB medium in a ration of $1: 100$.

Inactivation and aseptic examination of bacteria: To the total liquid TSB culture $0.4 \%$ formaldehyde to inactivate and then the inactivated culture was cultured in an oven at $37^{\circ} \mathrm{C}$ for $24 \mathrm{~h}$. Finally, the bacteria solution was taken to streak on the TSA plate to culture at $37^{\circ} \mathrm{C}$ for $24-48 \mathrm{~h}$ and then the result was observed.

Emulsification of the antigen: The above bacteria solution was centrifuged at $3000 \mathrm{r} \mathrm{min}^{-1}$ for $20 \mathrm{~min}$ and the supernatant was discarded. It was washed 3 times with sterilized $0.1 \mathrm{~mol} \mathrm{~L}^{-1} \mathrm{PBS}$ ( $\mathrm{pH} 7.4$ ) and the bacteria content was adjusted to $1 \times 10^{9} \mathrm{cfu} \mathrm{mL}^{-1}$. The bacteria solution was mixed with complete and incomplete Freund's 
adjuvant at the same amount till oil in water emulsion was formed. If the emulsion was not laminated it would be suitable for use.

Immunization procedure: In the first immunization, the mixing emulsion between complete Freund's adjuvant and the bacteria solution was used to immunize 4 piglets at the age of about 2 weeks by means of subcutaneous injection of $3 \mathrm{~mL}$ at multiple sites in the neck for each piglet. The second and third immunizations were performed on the 14 th day and on the 28th day, respectively by both adopting the mixing emulsion of incomplete Freund's adjuvant and the same method as that in the first immunization. About 1 week after the third immunization, $3 \mathrm{~mL}$ living bacteria solution was injected at the auricular vein of the piglets to enhance the immunization. About 1 week later blood sample was selected at the auricular vein. The antibody was detected with agar diffusion test and if notable precipitate was formed blood sample was collected from the heart of the rabbits. The collected sample was stored with the same method as the negative serum.

Preparation of negative serum: The piglets was fed for 3 days to ensure that they were normal. Blood sample was collected at the auricular vein. The collected blood sample was placed in an oven at $37^{\circ} \mathrm{C}$ for $1 \mathrm{~h}$ and then was placed in a refrigerator at $4^{\circ} \mathrm{C}$ overnight to isolate the serum. The isolated serum was centrifuged at $5000 \mathrm{r} \mathrm{min}^{-1}$ for $15 \mathrm{~min}$ and the supernatant was pipetted into different centrifuge tubes for storing at $-20^{\circ} \mathrm{C}$.

Preparation of coating antigen: Firstly the strain was streaked on the TSA plate to culture at $37^{\circ} \mathrm{C}$ for $24 \mathrm{~h}$. Then, the single clone was picked up to streak again on two TSA plates to culture at $37^{\circ} \mathrm{C}$ for $16 \mathrm{~h}$. At the same time, the single clone was picked up to inoculate in the liquid TSB medium to culture on a shaker at $200 \mathrm{r} \mathrm{min}^{-1}$ at $37^{\circ} \mathrm{C}$ for $16 \mathrm{~h}$. The bacteria solution in a ration of $1: 100$ was taken to inoculate in the fresh TSM medium to conduct scaled-up culture for $16 \mathrm{~h}$. Then, the clones on the plate was washed off with sterilized PBS buffer to add into the liquid medium. The bacteria solution was centrifuged at $3000 \mathrm{r} \mathrm{min}^{-1}$ for $20 \mathrm{~min}$ and the supernatant was discarded; sterilized $0.1 \mathrm{~mol} \mathrm{~L}^{-1} \mathrm{PBS}$ buffer ( $\mathrm{pH} 7.4$ ) was added to mix well by shaking, the bacteria solution was centrifuged at $3000 \mathrm{r} \mathrm{min}^{-1}$ for $20 \mathrm{~min}$ and the supernatant was discarded; the above steps were repeated several times to wash the bacteria solution. Finally, suitable amount of PBS in a volume ratio of $1: 10$ between bacteria solution and PBS and the supernatant was taken to perform filter with a filtering unit. The filtered antigen solution was detected with a nucleotide-protein detector to determine the antigen concentration, then merthiolate in the final concentration of $0.1 \mathrm{~g} \mathrm{~L}^{-1}$ was added to the antigen solution for storing at $-20^{\circ} \mathrm{C}$.

Manipulation of indirect ELISA Method: The ultrosonicated antigen was diluted with the coating liquor at a ratio of $1: 100$ and $50 \mu \mathrm{L}$ of the diluted antigen solution was added to each well and the ELISA plate was incubated at $37^{\circ} \mathrm{C}$ for $2 \mathrm{~h}$ and then transferred into a refrigerator at $4^{\circ} \mathrm{C}$ overnight for antigen-coating. On the next day each well was washed 3 times for $3 \mathrm{~min}$ for each with PBS buffer and padded dry; then the blocking buffer containing BSA was added, $50 \mu \mathrm{L}$ per well and the plate was incubated at $37^{\circ} \mathrm{C}$ for $1 \mathrm{~h}$ and then taken out for padding dry. The serum diluted with $\mathrm{PBS}$ buffer in a ratio of 1:60, $50 \mu \mathrm{L}$ per well and meanwhile the negative and positive serum control wells were set up. The plate was incubated at $37^{\circ} \mathrm{C}$ for $1 \mathrm{~h}$ and then taken out for padding dry. The rabbit anti-pig IgG-HRP was diluted in a ratio of 1:5000 and the diluted solution was added, $50 \mu \mathrm{L}$ per well. The plate was incubated at $37^{\circ} \mathrm{C}$ for $1 \mathrm{~h}$ and then taken out for padding dry. The substrate color development solution of $\mathrm{OPD}-\mathrm{H}_{2} \mathrm{O}_{2}$ prepared newly was added and the color was developed in the dark at $37^{\circ} \mathrm{C}$ for $15 \mathrm{~min}$. The stop solution of $2 \mathrm{~mol} \mathrm{~L}^{-1} \mathrm{H}_{2} \mathrm{SO}_{4}$ was added, $50 \mu \mathrm{L}$ per well and then the $D_{490}$ m value was measured in a ELISA reader, the $P / N$ value was calculated and $P / N \geq 2$ was judged as positive reaction.

\section{Determination of ELISA reaction conditions Determination of optimal antigen-coating concentration and optimal serum dilution ratio: Optimal antigen-coating} concentration and optimal serum dilution ratio were determined with Matrix Titration Method. The ultrsonicated antigen was diluted in ratios of 1:50, 1:100, $1: 200,1: 400$ and $1: 800$, respectively and added to the wells in line A-E of the 96 well ELISA plate.

The negative serum and the positive serum were diluted in ratios of $1: 40,1: 80,1: 160,1: 320$ and $1: 640$ and added to the wells in row $1-5$ and row 7-11. The manipulation of indirect ELISA was repeated twice and the average $\mathrm{P} / \mathrm{N}$ values were calculated. The antigen concentration and the serum dilution ratio corresponding to the maximum $\mathrm{P} / \mathrm{N}$ value were determined as the optimal ones.

Determination of optimal dilution ratio of the secondary enzyme-labeled antibody: The secondary antibody IgG was diluted in ratios of 1:2000, 1:3000, 1:4000, 1:5000, $1: 6000$, respectively. The $\mathrm{P} / \mathrm{N}$ values were calculated in accordance with ELISA manipulation procedure and the dilution ratio corresponding to the maximum $\mathrm{P} / \mathrm{N}$ value was determined as the optimal one. 
Determination of optimal coating time: The antigen was diluted in a ratio of $1: 100$ for coating. The test contains 4 groups: at $37^{\circ} \mathrm{C}$ for $1 \mathrm{~h}$ and then at $4^{\circ} \mathrm{C}$ overnight; at $37^{\circ} \mathrm{C}$ for $2 \mathrm{~h}$ and then at $4^{\circ} \mathrm{C}$ overnight; at $37^{\circ} \mathrm{C}$ for $2 \mathrm{~h}$ and t at $4^{\circ} \mathrm{C}$ overnight. The known negative serum and the known positive serum were used to carry out indirect ELISA manipulation procedure in two groups for several times and the $\mathrm{D}_{490 \mathrm{~mm}}$ values were measured.

Determination of blocking conditions: Under the determined conditions and with the determined manipulation, PBST containing $1 \mathrm{~mL} \mathrm{~L}^{-1} \mathrm{BSA}$ and the one containing $5 \mathrm{~mL} \mathrm{~L}^{-1}$ degreased milk were used, respectively as the blocking solution were added $100 \mu \mathrm{L} /$ per well. Blocking was performed at $37^{\circ} \mathrm{C}$ for $30 \mathrm{~min}, 1 \mathrm{~h}, 1.5 \mathrm{~h}$, respectively. The known negative serum and the known positive serum were used to carry out indirect ELISA manipulation procedure in two groups for several times and the $D_{490 \mathrm{~mm}}$ values were measured to determine the optimal blocking conditions.

Determination of optimal antigen-antibody action time: The $\mathrm{D}_{490 \mathrm{~mm}}$ values were measured under the conditions of antigen-antibody action time of 30,60 and $90 \mathrm{~min}$, respectively. For every time point 2 wells were used to perform indirect ELISA manipulation and the average was calculated. The binding time for which the $\mathrm{D}_{490 \mathrm{~mm}}$ value of the positive serum approaches to 1 and the $\mathrm{P} / \mathrm{N}$ value reach the maximum was determined as the optimal antigen-antibody action time.

Determination of secondary enzyme-labeled antibody action time: The secondary enzyme-labeled antibody IgG was diluted in a ratio of 1:5000 and under action time of 30,60 and $90 \mathrm{~min}$ at $37^{\circ} \mathrm{C}$, for every time point 2 wells were used to perform indirect ELISA manipulation and the average was calculated. The binding time, for which the $\mathrm{D}_{490 \mathrm{~mm}}$ value of the positive serum approaches to 1 and the $\mathrm{P} / \mathrm{N}$ value reaches the maximum was determined as the optimal secondary enzyme-labeled antibody action time.

Determination of optimal substrate color-developing time: Under the above optimized conditions ELISA test was performed. After adding the substrate the reaction acts in the dark at $37^{\circ} \mathrm{C}$ for $10,15,20$ and $30 \mathrm{~min}$, respectively and then was stopped. For every time point 2 wells were used to perform indirect ELISA manipulation and the average was calculated. The binding time, for which the $\mathrm{D}_{490 \mathrm{~mm}}$ value of the positive serum approaches to 1 and the $\mathrm{P} / \mathrm{N}$ value reaches the maximum was determined as the optimal substrate color-developing time.
Determination of negative and positive reaction standards: About 20 serum samples detected to be negative with Clinical Indirect Coagulation test were detected with indirect ELISA. For each serum sample 2 wells were used and the average of 20 serum samples was calculated. Then, the average $\overline{\mathrm{X}}$ of $\mathrm{S} / \mathrm{N}$ and the Standard Deviation (SD) were calculated. The calculation formula to determine the threshold between negative and positive reactions was $\overline{\mathrm{X}}+2 \mathrm{SD}$.

Sensitivity test: The optimal coating antigen was selected, based on the optimized conditions in determination of optimal antigen-coating concentration and optimal serum dilution ratio and then the serum was diluted in ratios of $1: 10,1: 100,1: 1000,1: 10000$ and $1: 100000$ to determine the ELISA Method sensitivity.

Specificity test: The positive serum samples of Swine pasteurellosis, Haemophilus parasuis serovar 4, Actinobacillus pleuropneumoniae, Haemophilus parasuis serovar 5 prepared and stored by the laboratory were used as the control to perform indirect ELISA detection.

Repeatability test: About 10 positive serum samples were taken to measure the $\mathrm{D}_{490 \mathrm{~mm}}$ values at different time under the same conditions thus manipulation was repeated three times.

Clinical application: With the established indirect ELISA Method clinical pig serum samples to be detected were detected and the $\mathrm{D}_{490 \mathrm{~mm}}$ values were measured.

\section{RESULTS AND DISCUSSION}

Isolation culture of bacteria: The bacteria did not grow on the basic agar plate or the Maconey medium did not grow well on the fresh blood agar plate and the chocolate plate and grew well on the TSA plate and NAD fresh blood agar plate.

After culturing for $24 \mathrm{~h}$ on the TSA plate, the obtained clones exhibited pinpoint-shaped round, gray white, semitransparent and $0.5-1 \mathrm{~mm}$ in diameter. With microscopic examination of Gram-stained sample the bacteria was determined to be Gram negative. Morphology of the bacteria was multiple and exhibited filament, short rod and even ball in shape.

Result of Biochemical test: The Biochemical test result of the isolated strain was shown in Table 1. According the Biochemical test results, the suspected clones were picked up to inoculated on the fresh blood agar plate and 
hence, the obvious satellite phenomenon occurred. Near staphylococcus lawn the clones to be tested grew well but far from it none of the clone grew.

PCR detection: By PCR amplification with purified isolated bacteria as the template, through $10 \mathrm{~g} \mathrm{~L}^{-1}$ agarose gel electrophoresis it was found in the gel imaging system that there existed a specific band in size of about $791 \mathrm{bp}$, the specific PCR product was consistent with the expected length of the amplified fragment (Fig. 1).

Antibiotic Susceptibility test: Referring to the antimicrobial drug susceptibility test standard of WS/T 125-1999 Paper Disc method, the test was carried out in Clinical Trial Standard Institute (CLSI) and the detailed results were shown in Table 2 . The results revealed that the isolated strain was tolerable to only gentamycin, enrofloxacin, compound sulfamethoxazole and penicilin and highly susceptible to cephalosporin IV, cefotaxime, sulbactam, furaxone and chloromycetin.

Animal test: The mice in the challenge group were all dead while in the control group the mice were all normal. The blood sample from the heart of the mice was taken to streak on the TSA plate for culturing, the same strain was isolated which suggested that this bacteria may have strong virulence to mice. The PCR-amplified product fragment was consistent with that from the isolated strain.

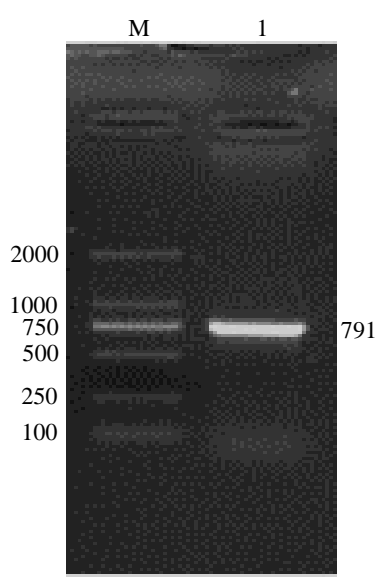

Fig. 1: PCR results from isolates M: Maker DL 2000; 1 : Isolates

\begin{tabular}{lclc}
\multicolumn{4}{l}{ Table 1: Result of Biochemical test } \\
\hline Pilot projects & Results & Pilot projects & Results \\
\hline Sucrose & + & Lactose & - \\
Xylose & - & Indole & - \\
Ornithine & + & Glucose & + \\
Catalase & + & Mannitol & - \\
Maltose & + & VP & - \\
$\mathrm{H}_{2} \mathrm{~S}$ & + & Indole & - \\
Nitrate reduction & + & - & - \\
\hline
\end{tabular}

+ represents the positive result; - represents the negative result
Identification of serovar: According to the manipulation described in 2.6 serovar of the isolated strain was identified. The result showed that isolated strain has stronger coagulation reaction with the positive serum of Hps serovar 5, in which white laminar coagulate was formed but no coagulation reaction with other standard positive serum samples and normal saline.

Determination of optimal ELISA reaction conditions Determination of optimal antigen-coating concentration and optimal serum dilution ratio: The results of the Matrix Titration Method showed when the ultrasonicated antigen was diluted in a ratio of 1:100 and the serum was diluted in a ratio of $1: 160$, the $\mathrm{P} / \mathrm{N}$ value was the maximum. The detailed results were shown in Table 3 .

Determination of optimal dilution ratio of the secondary enzyme-labeled antibody: The test results of different

Table 2: Result of Drug Sensitive test

\begin{tabular}{lcl}
\hline Drugs & Inhibit ory circle (mm) & Sensibility \\
\hline Gentamicin & 04 & Resistance \\
Cephalexin & 24 & Hypersensitive \\
Bactrim & 08 & Resistance \\
Cefotaxime & 34 & Hypersensitive \\
Kanamycin & 18 & Mid-range \\
Sulbactam & 26 & Hypersensitive \\
Furaxone & 20 & Hypersensitive \\
Chloramphenicol & 30 & Hypersensitive \\
Enrofloxacin base & 02 & Resistance \\
Florfenicol & 26 & Hypersensitive \\
Amikacin sulphate & 15 & Mid-range \\
Cefradine & 22 & Hypersensitive \\
Cefazolin & 20 & Hypersensitive \\
Fortum & 20 & Hypersensitive \\
Tetracycline & 14 & Mid-range \\
Polymyxin b & 14 & Mid-range \\
Rocephin & 23 & Hypersensitive \\
Cefalotin & 35 & Hypersensitive \\
Penicillin & 07 & Resistance \\
Streptomycin & 10 & Mid-range \\
\hline & &
\end{tabular}

Table 3: Determination of the optimal coating antigen concentration and the best dilution of serum Antigen dilution

\begin{tabular}{lcccccl}
\hline & Antigen dilution & & & & \\
Serum dilution & $1: 50$ & $1: 100$ & $1: 200$ & $1: 400$ & $1: 800$ & Results \\
\hline $1: 40$ & 0.821 & 0.943 & 0.915 & 0.875 & 0.867 & Positive \\
& 0.214 & 0.207 & 0.215 & 0.206 & 0.203 & Negative \\
& 3.836 & 4.556 & 4.256 & 4.248 & 4.271 & P/N \\
$1: 80$ & 0.913 & 0.935 & 0.924 & 0.926 & 0.890 & Positive \\
& 0.217 & 0.215 & 0.212 & 0.222 & 0.185 & Negative \\
& 4.207 & 4.349 & 4.358 & 4.171 & 4.811 & P/N \\
$1: 160$ & 1.038 & 1.219 & 1.123 & 1.084 & 1.070 & Positive \\
& 0.172 & 0.170 & 0.182 & 0.179 & 0.168 & Negative \\
& 6.035 & 7.170 & 6.170 & 6.056 & 6.369 & P/N \\
$1: 320$ & 1.010 & 0.992 & 0.956 & 0.897 & 0.828 & Positive \\
& 0.165 & 0.171 & 0.169 & 0.163 & 0.161 & Negative \\
& 6.121 & 5.801 & 5.657 & 5.503 & 5.143 & P/N \\
$1: 640$ & 0.895 & 0.979 & 0.948 & 0.89 & 0.801 & Positive \\
& 0.163 & 0.173 & 0.172 & 0.167 & 0.168 & Negative \\
& 5.491 & 5.659 & 5.512 & 5.329 & 4.768 & P/N \\
\hline
\end{tabular}


dilution ratio of the rabbit anti-pig IgG were shown in Table 4. It could be seen that when the dilution ratio of the secondary antibody was 1:5000 the $\mathrm{P} / \mathrm{N}$ value reached the maxium.

Determination of optimal coating time: $W$ ith indirect ELISA the $\mathrm{D}_{490 \mathrm{~mm}}$ values were measured at $37^{\circ} \mathrm{C}$ for $1 \mathrm{~h}$ and then at $4^{\circ} \mathrm{C}$ overnight, at $37^{\circ} \mathrm{C}$ for $2 \mathrm{~h}$ and then at $4^{\circ} \mathrm{C}$ overnight, at $37^{\circ} \mathrm{C}$ for $2 \mathrm{~h}$, at $4^{\circ} \mathrm{C}$ overnight, respectively. Since, the $\mathrm{D}_{490 \mathrm{~mm}}$ value 0.945 was the nearest to 1 and the maximum of the $\mathrm{P} / \mathrm{N}$ values was 6.217 , the optimal coating time was the condition, at $37^{\circ} \mathrm{C}$ for $2 \mathrm{~h}$ and then at $4^{\circ} \mathrm{C}$ overnight.

Determination of optimal blocking condition: The detection results indicated, when PBST containing $1 \mathrm{~mL} \mathrm{~L}^{-1}$ BSA was used to block for $1 \mathrm{~h}$, the value of the positive serum was the minimum and therefore the optimal blocking time was $1 \mathrm{~h}$.

Determination of optimal antigen-antibody action time: Because when the antigen-antibody action time was $60 \mathrm{~min}$, the $\mathrm{D}_{490 \mathrm{~mm}}$ value was 0.821 which is nearest to 1 and the $\mathrm{P} / \mathrm{N}$ value was the maximum, 5.906, $60 \mathrm{~min}$ was determined to be the optimal antigen-antibody action time.

Determination of secondary enzyme-labeled antibody action time: When the secondary enzyme-labeled antibody action time was $60 \mathrm{~min}$, the $\mathrm{D}_{490 \mathrm{~mm}}$ value was 0.847 which is nearest to 1 and the $P / N$ value was the maximum, 6.274 and therefore $60 \mathrm{~min}$ was determined to be the optimal secondary enzyme-labeled antibody action action time.

Determination of optimal substrate color-development time: When at $37^{\circ} \mathrm{C}$ in the dark the reaction lasted $15 \mathrm{~min}$, the $\mathrm{D}_{490 \mathrm{~mm}}$ value was 0.892 which is nearest to 1 and the $\mathrm{P} / \mathrm{N}$ value was the maximum, 6.110 and therefore $15 \mathrm{~min}$ was determined to be the optimal substrate colordevelopment time.

Determination of negative and positive reaction standards: After 20 serum samples detected to be negative with Clinical Indirect Coagulation test were detected with indirect ELISA, the measured $\mathrm{D}_{490 \mathrm{~mm}}$ values were divided by the $\mathrm{S} / \mathrm{N}$ values (Table 5) of the standard negative serum samples. By calculating according to the equation:

Table 4: Determination of the optimal dilution of peroxidase HRP secondary antibody

\begin{tabular}{lccccc} 
the optimal dilution & $1: 2000$ & $1: 3000$ & $1: 4000$ & $1: 5000$ & $1: 6000$ \\
\hline Positive serum & 0.992 & 1.088 & 1.139 & 1.185 & 1.129 \\
Negative serum & 0.214 & 0.203 & 0.186 & 0.172 & 0.169
\end{tabular}

$\underline{\mathrm{P} / \mathrm{N}}$

\begin{tabular}{lllll}
4.636 & 5.360 & 6.124 & 6.890 & 6.680 \\
\hline
\end{tabular}

$$
\mathrm{SD}=\sqrt{\frac{\sum\left(\mathrm{X}_{\mathrm{n}}-\overline{\mathrm{X}}\right)^{2}}{\mathrm{n}-1}}
$$

$\overline{\mathrm{X}}$ of 20 serum samples was 1.73 , the SD was 0.171 and hence $\overline{\mathrm{x}}+2 \mathrm{SD}$ to determine the threshold between the negative reaction and the positive one was 2.07 . Therefore when $\mathrm{S} / \mathrm{N} \geq 2.07$ for the serum to be detected, the reaction was judged to be positive.

Sensitivity test: When the coating antigen was diluted in a ratio of $1: 100$ and the serum was diluted in ratios of $1: 10$. $1: 100,1: 1000,1: 10000$ and $1: 100000$, the $\mathrm{P} / \mathrm{N}$ values were determined. The results were shown in Table 6. From Table 6 it could be seen that this method had high sensitivity.

Specificity test: Taking the negative serum as the control, the positive serum samples from Swine pasteurellosis, Haemophilus parasuis Serovar 4, Actinobacillus pleuropneumoniae, Haemophilus parasuis Serovar 5 were detected with the established indirect ELISA. The results were shown in Table 7.

From Table 7 except for the $D_{490 \mathrm{~mm}}$ values of the serum samples of Haemophilus parasuis Serovar 4 and 5 were greater than the threshold and the $\mathrm{P} / \mathrm{N}$ value was the biggest, those of other bacteria serum samples were all smaller than the threshold and these serum samples may be judged to be negative. This revealed that this indirect ELISA Method had high specificity.

\begin{tabular}{|c|c|c|c|}
\hline Serum No. & $\mathrm{S} / \mathrm{N}$ & Serum No. & $\mathrm{S} / \mathrm{N}$ \\
\hline 1 & 1.99 & 11 & 1.65 \\
\hline 2 & 2.21 & 12 & 1.53 \\
\hline 3 & 1.63 & 13 & 1.57 \\
\hline 4 & 1.71 & 14 & 1.82 \\
\hline 5 & 1.73 & 15 & 1.66 \\
\hline 6 & 1.87 & 16 & 1.57 \\
\hline 7 & 1.89 & 17 & 1.61 \\
\hline 8 & 1.77 & 18 & 1.61 \\
\hline 9 & 1.59 & 19 & 1.87 \\
\hline 10 & 1.55 & 20 & 1.75 \\
\hline
\end{tabular}

\begin{tabular}{lccccc}
\multicolumn{6}{l}{ Table 6: The result of Sensitivity test for indirect-ELISA } \\
\hline Antigen & Serum & & & & \\
- & ------ & & & \\
$1: 100$ & $1: 10$ & $1: 100$ & $1: 1000$ & $1: 10000$ & $1: 100000$ \\
\hline Positive & 1.200 & 1.100 & 0.800 & 0.750 & 0.500 \\
Negative & 0.173 & 0.182 & 0.193 & 0.179 & 0.168 \\
P/N & 6.936 & 6.064 & 4.145 & 4.190 & 2.976 \\
\hline
\end{tabular}

Table 7: The result of Pecificity test for indirect-ELISA

\begin{tabular}{lllllll}
\hline Serotypes & Pasteurella & E. coli & HPS4 & APP & HPS5 & Negative \\
\hline $\mathrm{D}_{490 \mathrm{~mm}}$ & 0.243 & 0.217 & 1.216 & 0.293 & 1.291 & 0.165 \\
$\mathrm{P} / \mathrm{N}$ & 1.473 & 1.315 & 7.370 & 1.776 & 7.824 & 1.000 \\
Result & - & - & + & - & + & -
\end{tabular}


Table 8: The reproducibility of ELISA in detection of serum samples

\begin{tabular}{|c|c|c|c|c|c|c|c|c|c|c|}
\hline \multirow[b]{2}{*}{ Detect the serial number } & \multicolumn{10}{|c|}{ Sample No. } \\
\hline & 1 & 2 & 3 & 4 & 5 & 6 & 7 & 8 & 9 & 10 \\
\hline First & 0.913 & 0.909 & 0.886 & 0.929 & 0.893 & 0.898 & 0.907 & 0.931 & 0.921 & 0.917 \\
\hline Second & 0.892 & 0.915 & 0.897 & 0.868 & 0.925 & 0.848 & 0.874 & 0.929 & 0.917 & 0.911 \\
\hline Third & 0.835 & 0.879 & 0.883 & 0.919 & 0.851 & 0.852 & 0.929 & 0.905 & 0.902 & 0.903 \\
\hline Result & + & + & + & + & + & + & + & + & + & + \\
\hline
\end{tabular}

Repeatability test: The $\mathrm{D}_{490 \mathrm{~mm}}$ values (Table 8) of 10 positive serum samples at different time had small change range and this indicated that this method had good repeatability.

Results of clinical test: Two batches of serum samples to be detected in total quantity of 120 were detected with the indirect ELISA Method established in this study. The results showed that 17 serum samples were positive and the detection rate was $22.5 \%$.

Haemophilus parasuis is a bacterium which is most hard to culture and usually is very difficult to isolate the pure culture of those samples of animals with the disease and especially after those pigs with the disease are treated with antibiotics isolation of this bacterium becomes even more complicated. The requirements for growth environment of Haemophilus parasuis are most strict and its growth depends on exogenous NAD (factor V) (Kielstein et al., 2001). Ideal samples of Haemophilus parasuis for isolation should be collected from those pigs with acute infection which manifest the characteristic symptoms of this disease and are not treated with antibiotics. Therefore, isolation and identification of this pathogen has big difficulty while is critical in prevention and treatment of the disease caused by it because only if the pathogen is isolated further detection work such as antibiotic susceptibility test or serovar classification which has great benefit for control of the disease can be carried out. According to the results of clone morphology, biochemical characteristics and satellite phenomenon, the isolated strain in this study can be judged preliminarily as Haemophilus parasuis; with $\mathrm{PCR}$ amplification, the target DNA fragment in the same length as expected has been amplified successfully and this proves that the isolates strain is just HPS. However, the results of Antibiotic Susceptibility test have indicate that this isolates strain is tolerable to gentamycin, enrofloxacin, compound sulfamethoxazole and penicilin and highly susceptible to cephalosporin IV, cefotaxime, sulbactam, furaxone, chloromycetin which has certain difference from the related reports home and abroad. This may be associated with difference in the susceptibility of the HPS strains of different serovars from different regions to the same antibiotic. Meanwhile, the same antibiotic has different susceptibility to different strains. And hence, clinical administration of antibiotics should be performed under the instruction of the results of related Antibiotic Susceptibility tests. It should be avoided that improper antibiotic administration leads to development of the antibiotic-resistant strain. For infection of Haemophilus parasuis in different pig farms, a set of immunization procedure with strong purpose should be formulated and the susceptible drug should be selected to be used for treatment. In Serovar Identification test, the isolated strain has reaction with the HPS Serovar 5 standard serum which produce white laminar coagulate but had no reaction with other serum samples and normal saline which reveals that the this strain belongs to Serovar 5. Some related serum epidemic investigations carried out in other countries have reported the Serovar 4,5 and 13 were most epidemical in German, the USA, Canada, Japan and Spain and $>20 \%$ of the isolated strains can not be determined (Cai et al., 2005). From this researchers can see, epidemical law of the serovars of Haemophilus parasuis in Sichuan is basically similar to that in other countries but has certain difference.

Among Serological Detection Methods, the indirect ELISA Method is very sensitive, specific and more accurate, more sensitive and more objective than the indirect coagulation test (Oliveira, 2003; Yin et al., 2004). Referring to the method reported by Xu et al. (2010) and Morozumi and Nicolet (1986), the bacteria solution with concentration of inactivated Haemophilus parasuis, $1 \times 10^{9} \mathrm{cfu} \mathrm{\textrm {mL } ^ { - }}$ was adopted as the immunogen and enhancing immunization after the third immunization had stronger effect. Selection of suitable coating antigen is the critical step for establishment of indirect ELISA Method. Shi et al. (2007) and Wang et al. (2006), selected capsule polysaccharide and complete bacterium as the coating antigen, respectively to establish the indirect ELISA Methods which had ideal test results and could be used for diagnosis and epidemic investigation. Feng et al. (2009) selected the supernatant of the ultraosonicated bacteria solution as the immunogen which contains a great amount of soluble protein and polysaccharide antigen of the bacteria which often are used as the antigen for Serological Diagnosis Methods. 


\section{CONCLUSION}

This study, based on the supernatant of the ultrosonicated bacteria solution, the coating antigen was prepared by filtering with filtering unit, a specific and sensitive indirect ELISA Method was established successfully which provided scientific evidence and a reliable antibody detection way for prevention and treatment of the Haemophilus parasuis disease in this region. Due to less impurity in the filtered supernatant, soluble protein and polysaccharide antigen are purer and interference for antigen coating reduces much and hence the coating antigen has characters of easy preparation, simple quality control, broad spectrum and high sensitivity. In this study researchers used the established Indirect ElISA Method to detect 120 serum samples to be detected and the positive detection rate was $22.5 \%$ which is almost consistent with that reported by Zhou et al. (2009) which suggests that epidemic situation of HPS in Sichuan should be concerned more.

\section{ACKNOWLEDGEMENTS}

This study was supported by the Ministry of Education innovates the team project the Yangtze River Scholar and Innovation Team Development plan of China (Grant No.: IRT0848) and double support projects of Sichuan Agricultural University of China.

\section{REFERENCES}

Cai, X.W., Z.F. Liu and H.Q. Chen, 2005. Isolation and culture of haemophilus parasuis and its serovar identificaiton. Chinese Acad. J. Huazhong Agric. Univ., 24: 55-58.

Feng, X.M., Y.F. Chu and Y. He, 2009. Establishment and application of indirect ELISA method for detection of haemophilus parasuis. China Vet. Sci., 39: 597-601.

Kielstein, P., H. Wuthe and O. Angen, 2001. Phenotypic and genetic characterization of NAD-dependent Pasteurellaceae from the respiratory tract of pigs and their possible pathogenetic importance. Vet. Microbiol., 81: 243-255.
Li, L.R., Y. Wang and Y. Song, 2011. Isolation and identification of haemophilus parasuis disease and antibiotic susceptibility test. Progress Anim. Med. China, 32: 115-118.

Morozumi, T. and J. Nicolet, 1986. Some antigenic properties of Haemophilus parasuis and a proposal for serological classification. J. Clin. Microbiol., 23: $1022-1025$.

Oliveira, S., 2003. Haemophilus parasuis, diagnosis, epidemiology and control. Minnesota, University of Minnesota, 129-134.

Oliveira, S., L. Batista, M. Torremorell and S. Oliveira, 2001. Expe rimental colonization of piglets and gilts with systemic strains of Haemophilus parasuis and Streptococcus suis to prevent disease. Can. J. Vet. Res., 65: 161-167.

Oliveria, S. and C. Pijioan, 2004. Haemophilus parasuis: Newtrends on diagnosis, epidemiology and control. Vet. Mierobiol., 99: 1-12.

Shi, B., Y.W. Cui and F. Jia, 2007. Indirect coagulation test of haemophilus parasuis serovar 5 and establishment of indirect ELISA antibody method. China Vet. Sci., 37: $964-968$

Straw, U.S.A., L. Wenjun and Z. Zhongqiu, 1998. As Translators: Swine Pathology. 8 Edn., China Agricultural University Press, Beijing, China pp: 407-416.

Wang, Y., W.T. Xia and P. Jiang, 2006. Establishment of Indirect ELISA Method for Detection of Haemophilus parasuis. China Anim. Usbandry Anim. Med., 38: 5-6.

Xu, Y.D., Z.F. Wang and W.H. Zhu, 2010. Preparation and application of rabbit serum of haemophilus parasuis. Chinese Bull. Agric. Sci., 26: 14-16.

Yin, X.F., P. Jiang and Y.X. Deng, 2004. Isolation and identification of haemophilus parasuis. China Anim. Husbandry Anim Med., 36: 6-8.

Zhou, X.B., K.G. Zhou and J.L. Lei, 2009. Progress in research and control of Haemophilus parasuis disease. Proceedings of Global Swine Industry Forum and 2009 China Swine Industry Development Confession. 